\title{
Profit Sharing and Outsourcing under Labor Market Imperfection
}

\author{
Erkki Koskela \\ University of Helsinki and HECER \\ and \\ Jan König \\ Freie Universität Berlin
}

Discussion Paper No. 311

December 2010

ISSN 1795-0562

HECER - Helsinki Center of Economic Research, P.O. Box 17 (Arkadiankatu 7), FI-00014 University of Helsinki, FINLAND, Tel +358-9-191-28780, Fax +358-9-191-28781, E-mail info-hecer@helsinki.fi, Internet www.hecer.fi 


\title{
Profit Sharing and Outsourcing under Labor Market Imperfection*
}

\begin{abstract}
We combine profit sharing and outsourcing, when the wage rate is set by a labor union to analyze how the implementation of profit sharing affects individual effort and the wage and thus outsourcing. We find that profit sharing and the wage have an individual effortaugmenting effect and therefore increase productivity. We also find that the wage effect of profit sharing in general is ambiguous. There is a wage decreasing substitution effect, but on the other hand, there is a wage increasing effect via labor demand elasticity and effort so that outsourcing and employment effects are also ambiguous. Furthermore, we show under which condition the firm will implement a profit sharing scheme.
\end{abstract}

JEL classification: E23, E24, J23, J33, J82

Keywords: flexible outsourcing, profit sharing, employee effort, labor market imperfection.

Erkki Koskela

Department of Economics

University of Helsinki

P.O. Box 17 (Arkadiankatu 7)

FI-00014 University of Helsinki

FINLAND

e-mail: erkki.koskela@helsinki.fi
Jan König

School of Business \& Economics

Freie Universität Berlin

Boltzmannstr. 20

DE-14915 Berlin

GERMANY

e-mail : jan.koenig@fu-berlin.de

* Koskela also thanks the Academy of Finland (grant No. 1217622) for further financial support and Freie Universitaet Berlin for good hospitality. König thanks University of Helsinki for good hospitality. 


\section{Introduction}

It is often argued that high wage or labor costs in Western Europe are the driving force behind the increasing business practice of international outsourcing across industries (see e.g. Stefanova (2006) and Amiti and Wei (2005)). One reason for the wage gap between Western European and Eastern European or Asian countries is the difference in labor market institutions. Typically in Western Europe, wages for low-skilled workers are set by the government via minimum wage arrangements or determined by bilateral bargaining between firms or employer federations and labor unions. On the contrary, unions in Eastern European or Asian countries are much weaker or wages are determined by market forces. Therefore, flexible outsourcing, which is decided after knowing the domestic production costs, is a significant threat for employment in the low-skilled segment in industrialized countries. To work against this threat and make domestic production more attractive, lower wages or higher productivity are needed. While the first call due to the described labor market structure in Western Europe is difficult to realize, the second postulation might be realized by introducing a profit sharing scheme, which is often expressed by labor unions or politics. Due to this scheme from the worker point of view, the relationship of income and wage will be released, while from the firm's perspective costs and wages are decoupled. Thus, it is possible to decrease the wage but to generate the same income.

Although profit sharing is an important phenomenon in OECD countries ${ }^{1}$, the productivity effect is ambiguous. ${ }^{2}$ On the one hand it is argued that due to profit sharing motivation and identification with the firm is stimulated and thus effort respectively productivity increases. On the other hand, there could be free riding behaviour, since if there are $n$ employees and profits will be equally distributed, an individual receives only $1 / n$ of the extra profit, which will lead to fewer incentives to increase effort.

However, profit sharing also affects the wage bargaining. Concerning the wage effect of profit sharing, several studies confirm that higher profit sharing decreases the bargained wage ${ }^{3}$, since higher wages decrease the profit of a firm and

Pendleton et al. (2001) have presented detailed data on profit sharing schemes in 14 OECD countries. For further evidence regarding the incidence of profit sharing, see also Estrin et al. (1997) and Conyon and Freeman (2004).

2 For an increasing effect on productivity, see Cable and Fitzroy (1980), while, Jensen and Meckling (1979), and Kruse (1993) demonstrate negative productivity effects of profit sharing.

See e.g. Weitzman (1987), Wadhwani (1988), Fung (1989) and Holmlund (1990). However, there are also empirical studies, such as Wadhwani and Wall (1990) and Kraft and Ugarkovic (2005), which show that profit sharing does not reduce the wage. 
thus the profit income of the worker. Due to this loss, the union's marginal costs of an increasing wage are higher and therefore, higher profit sharing will induce a less aggressive wage setting.

Bringing together the finding concerning the relationship between domestic wage and outsourcing plus the possible wage decreasing effect of profit sharing, one would expect that profit sharing lowers the outsourcing demand. However, as it is shown in Koskela and König (2010), profit sharing decreases the bargained wage and thus outsourcing. But if the labor union also sets the effort or productivity level, the firm will desist from implementing a profit sharing scheme.

In contrast to Koskela and König (2010), in this paper we combine profit sharing and outsourcing, when the wage rate is set by a labor union, but effort is decided individual by the worker. In this context, we analyze the impacts of profit sharing on a firm's incentive to outsource domestic production by answering the following questions: First, how does the implementation of profit sharing affect effort and thus productivity? Second, how does profit sharing influence the wage and thus outsourcing demand? Third, will the firm implement a profit sharing scheme, if workers decide individually about effort provision?

We find that profit sharing and the wage level have an individual effortaugmenting effect and therefore increase productivity. This results from the fact that higher profit sharing increases the income, which sets an incentive to increase the profit due to higher effort. Concerning our second question, we demonstrate that the wage effect of profit sharing is ambiguous. On the one hand, there is a wage decreasing substitution effect, but on the other hand, there is a wage increasing effect via labor demand elasticity. Therefore, the outsourcing or employment effect is also ambiguous. Regarding our third question, we find that under certain circumstances there will be a profit sharing scheme, which characterizes due to the modeling of effort determination the central difference between the results of this paper and those of Koskela and König (2010).

We proceed as follows. Section II presents the time sequences of decisions. Also, the labor and outsourcing demand and employee effort are presented. Section III investigates the wage formation by a monopoly labor union and the optimal profit share. Finally, we present our conclusions in section IV.

\section{The Model}

We assume that the output depends not only on domestic labor and international outsourcing, but also on the effort by workers, i.e. the workers' 
productivity. This lies in conformity with the efficiency wage hypothesis. ${ }^{4} \mathrm{We}$ analyze a timing decision, which captures the idea that the representative firm is flexible to decide about outsourcing simultaneously with domestic labor demand, but commits to profit sharing before wage determination. After the firm has decided about profit sharing, the monopoly labor union sets the wage given the profit share level. Knowing the base wage the representative firm determines outsourcing and employment. Once the wage and profit share level are known, the representative worker decides on effort provision. We summarize these timing decisions in Figure 1. The decisions at each stage are analyzed by using backward induction.

Figure 1: sequences of decisions

\begin{tabular}{lll} 
stage 1 & stage 2 & stage 3 \\
\hline profit & wage & outsourcing $M$, labor demand $L$ \\
sharing $\tau$ & formation $w$ & and effort determination $e_{i}$
\end{tabular}

As we mentioned, output depends on effort, domestic labor and outsourcing. We combine these inputs in a concave production function which is characterize as

$$
F(\bar{e} L, M)=\left((\bar{e} L)^{\frac{\sigma-1}{\sigma}}+M^{\frac{\sigma-1}{\sigma}}\right)^{\frac{\alpha \sigma}{\sigma-1}}, \text { with } 0<\alpha<1
$$

where the price of the output is normalized to unity, $L$ is the amount of domestic labor and $M$ the firm's input acquired from external suppliers through outsourcing. The average effort of the firm's worker is described by $\bar{e}$, where the average effort is defined as $\bar{e}=\frac{1}{L} \sum_{i=1}^{L} e_{i}$, so that the impact of provision of an additional unit of effort by a single worker is $\frac{\partial \bar{e}}{\partial e_{i}}=\frac{1}{L} .^{5}$ The parameter $\sigma$ indicates the elasticity of substitution between effective labor and outsourcing. Following the reasonable assumption that there is a substitutability between them, we focus on $1<\sigma<\infty$. For indicating decreasing returns to scale, we further assume $0<\alpha<1$.

See e.g. the book edited by Akerlof and Yellen (1986), which includes the main initial efficiency wage papers about (i) shirking models, (ii) labor turnover models, (iii) adverse selection models and (iv) sociological models.

A specification, which is also common in the literature, describes effort as the fraction of working hours that the worker actually works. Since the number of working hours is normalized to 1 , the choice of an individual is $e_{i} \in(0 ; 1)$ and thus $\left(1-e_{i}\right)$ characterizes the fraction of time spent shirking. Following this, $\bar{e} L$ is the whole actual working time. 


\section{II.1. Outsourcing and Domestic Labor Demand}

The firm decides on domestic labor and outsourcing to maximize the profit function

$$
\max _{L ; M}(1-\tau) \cdot \pi=(1-\tau) \cdot[F-w \cdot L-c \cdot M]
$$

by taking the average effort, $\bar{e}$, wage, $w$, and profit sharing, $\tau$, as given. For the costs of outsourcing $c$ we assume that they include other costs as transport and communication costs or costs for monitoring and quality control. However, to be simple, we sum these kinds of costs and assume that the unit costs of outsourcing are constant.

Solving the first-order conditions of (2), we can yield the conditional labor and outsourcing demand

$$
\begin{aligned}
& L=\left[(w / \bar{e})^{1-\sigma}+c^{1-\sigma}\right]^{\frac{\sigma}{1-\sigma}} \cdot w^{-\sigma} \cdot \bar{e}^{\sigma-1} \cdot F^{\frac{1}{\alpha}}, \\
& M=\left[(w / \bar{e})^{1-\sigma}+c^{1-\sigma}\right]^{\frac{\sigma}{1-\sigma}} \cdot c^{-\sigma} \cdot F^{\frac{1}{\alpha}} .
\end{aligned}
$$

In the case of substitutability, we have to secure that $F_{L M}<0$ respectively $F_{M L}<0$. For guaranteeing this, we have to assume $\sigma>\frac{1}{1-\alpha}$ for our analysis. One can show from the conditional demand functions that domestic labor demand is a negative function of wage and a positive function of both outsourcing costs and effort, while the external procurement is a positive function of domestic wage rate and a negative function of outsourcing costs and effort. However, equation (3a) shows also that the conditional labor demand does not directly depend on profit sharing, which also lies in conformity with empirics. ${ }^{6}$

At this stage, we can look at the direct labor demand elasticities. Defining the direct own wage elasticity of the labor as $\eta_{w}=-\frac{\partial L}{\partial w} \frac{w}{L}$ and the direct effort elasticity of the labor as $\eta_{\bar{e}}=\frac{\partial L}{\partial \bar{e}} \frac{\bar{e}}{L}$, we obtain

$$
\begin{aligned}
& \eta_{w}=\sigma(1-s)+\frac{s}{1-\alpha}, \\
& \eta_{\bar{e}}=\eta_{w}-1>0
\end{aligned}
$$


where $s=\frac{(w / \bar{e})^{1-\sigma}}{(w / \bar{e})^{1-\sigma}+c^{1-\sigma}}$ characterizes the cost share of domestic labor (see Appendix A for the detailed mathematical derivation).

\section{II.2. Individual Employee Effort}

By following the efficiency wage literature, we assume for the employed worker that the utility function is additively separable, where the utility depends positively on the income and negatively on the disutility of effort. The employed worker receives an income $y$, which includes both the wage $w$ and the profit income $\tau \frac{\pi}{L}$ so that the overall remuneration is $y=w+\tau \frac{\pi}{L}$. The idea behind this is that the workers are a team, where the whole team gets the profit share $\tau \cdot \pi$, which is distributed equally to the member. However, to get the profit income, requires effort provision by a single worker. Since the worker dislikes effort provision, it is associated with a disutility, which can be described by the convex function $g(e)$, where $\quad g(e)=\gamma \cdot e^{1 / \gamma} \quad$ with $\quad 0<\gamma<1 \quad$ so that $\quad g^{\prime}(e)=e^{(1 / \gamma)-1}>0 \quad$ and $g^{\prime \prime}(e)=[(1 / \gamma)-1] e^{(1 / \gamma)-2}>0$.

Since the profit is equally distributed among the members, every (homogenous) worker gets the same per capita profit income, but he/she realizes the individual disutility for providing a certain effort level. Thus, there is room for freerider behavior by the single worker, which means that there is an incentive for shirking. The biggest problem of the firm's owner is to solve this moral hazard problem and to verify the individual effort. However, in the discussion of the freerider problem, the interactions of group members as well as peer pressure are often neglected. Due to the implementation of profit sharing, there are incentives in the group to internalize the externalities of free-riding and avoid shirking, since it sets an incentive to observe each other and interact. ${ }^{7}$ This may build up a peer pressure to provide the effort resulting from individual utility maximization and eliminate the moral hazard problem concerning the free-rider behavior. Following Kandel and Lazear (1992), we motivate this peer pressure as a social group norm. Due to the observation, the individual feels ashamed or guilty, if the individual effort is below this norm, since it lowers the income for each of the team members. However, an effort above the norm also decreases the individual utility, since now the other team members feel ashamed. Thus, any deviation from the norm leads to a utility loss.

See Holmstrom (1982), Holmstrom and Milgrom (1990) and Varian (1990). Radner (1986) shows, that in repeated games the free-rider problem can be eliminated even if the players cannot observe other players' actions or information, but can observe the consequences. 
Therefore, the peer pressure function can be written as $P\left(e_{i}\right)=\left(\tilde{e}-e_{i}\right)^{2}$, where $\tilde{e}$ is the social norm and defined as the average effort of all workers other than $i{ }^{8}$

From this framework, we can write the utility of a single employed individual in (5a) and of an unemployed individual in (5b)

$$
\begin{aligned}
& v=w+\tau \frac{\pi}{L}-\gamma e_{i}^{1 / \gamma}-\left(\tilde{e}-e_{i}\right)^{2}, \\
& \bar{v}=b .
\end{aligned}
$$

The worker's problem is to choose the level of individual effort to maximize its utility. For simplicity, suppose that observation of team member is costless and that the group norm is not affected by the individual effort, i.e. $\frac{\partial \widetilde{e}}{\partial e_{i}}=0 .{ }^{9}$ Thus, the individually provided effort level results from individual utility maximization of (5a) with respect to effort, which yields the first-order condition ${ }^{10}$

$$
\frac{\partial v}{\partial e}=\frac{\tau}{L} \frac{\partial \pi}{\partial e}-e^{(1 / \gamma)-1}+2(\tilde{e}-e)
$$

Using our production function and $\bar{e}=\frac{1}{L} \sum_{i=1}^{H} e_{i}$, which leads to $\frac{\partial \bar{e}}{\partial e_{i}}=\frac{1}{L}$, we obtain for the individual effect on profit $\partial \pi / \partial e=w / \bar{e} \cdot{ }^{11}$ Due to our assumption of Nashbehaviour, where every worker takes the effort of the others as given, the individual chooses an effort level equal to the group norm. However, every group member faces the same calculus, which means that the group norm corresponds to the average effort level. Therefore, the individual effort equals the average effort level and thus the effort level which would be chosen without any peer pressure, i.e. we have $e=\tilde{e}=\bar{e}$. Using this, we get from solving equation (6) the effort function

$$
e=\bar{e}=\left(\frac{\tau \cdot w}{L}\right)^{\gamma}
$$

8 We assume that every group member can verify the effort of the others, but the firm owner cannot do this. In our specification, the punishment of shirking or overly motivated members is an individual utility loss and not an income loss, and can be interpreted as mental harassment or social exclusion. taking the effort of others as given. So there is no effect of effort provision by the other workers and thus no effect on the social norm. See also Lin et al. (2002). 
From equation (7), we see that the optimal effort by the representative worker is influenced by the income parts, but outsourcing will have no direct effect.

Since changes in wage and profit income affect all workers, every single worker will adjust his/her effort and thus the average effort will change. We derive these effects by taking the differential of effort function (7), which yields $\frac{d \bar{e}}{d w}=\frac{\gamma\left(1+\eta_{w}\right)}{1+\gamma \cdot\left(\eta_{w}-1\right)} \frac{\bar{e}}{w}>0$ and $\frac{d \bar{e}}{d \tau}=\frac{\gamma}{1+\gamma \cdot\left(\eta_{w}-1\right)} \frac{\bar{e}}{\tau}>0$, so that the wage and profit sharing enhance productivity by increasing effort provision and positively affect labor demand indirectly, which lies in conformity with empirics. ${ }^{12}$

For the following analysis, the wage elasticity of effort becomes important. In our framework we find,

$$
\phi=\frac{d \bar{e}}{d w} \frac{w}{\bar{e}}=\frac{\gamma \cdot\left(1+\eta_{w}\right)}{1-\gamma \cdot\left(\eta_{w}-1\right)}\left\{\begin{array}{l}
< \\
=\} \\
>
\end{array} \text { as } \gamma\left\{\begin{array}{l}
< \\
= \\
>
\end{array}\right\} \frac{1}{2}\right.
$$

so that the elasticity of effort in terms of wage is only one, if we have the specific parameter $\gamma=1 / 2$ for the disutility of effort. ${ }^{13}$ According to (8), the effort elasticity increases (decreases) if the disutility of effort becomes less (more) convex. Since we are interested in the effect of profit sharing if the wage is determined by a labor union, we have to assume that $\gamma<1 / 2$. The reason for this assumption is that only in this case, the wage setting by the labor union would be binding for the firm.

For the effort elasticity concerning profit sharing we found that it is positive, but smaller than one, i.e. $\mu=\frac{d \bar{e}}{d \tau} \frac{\tau}{\bar{e}}=\frac{\gamma}{1+\gamma \cdot\left(\eta_{w}-1\right)} \in(0 ; 1)$.

We can now summarize our findings as.

Proposition 1: Profit sharing and the base wage have an individual effort-augmenting effect and thus increase productivity, whereas the wage elasticity of effort depends on the parameter of disutility of effort so that it can be smaller, equal to or higher than one.

12 See e.g. Booth and Frank (1999), Cable and Wilson (1990), Cahuc and Dormont (1997), Kruse (1992), Lynn Hannan (2005) and Wadhwani and Wall (1990).

13 In a dynamic efficiency wage model without outsourcing, Jellal and Zenou (2000) have obtained the same result in terms of effort wage elasticity. 
For the above mentioned reason, in the following analysis, we concentrate on the case in which the wage elasticity of effort is smaller than one, i.e. $\phi<1$.

\section{Wage Formation by Monopoly Labor Union and Committed Profit Sharing}

Now we analyze stage 2 , when the representative firm commits to profit sharing before the wage formation.

\section{III.1. Wage Formation under Committed Profit Sharing}

We first analyze the wage formation by the monopoly union (see also Cahuc and Zylberberg (2004), p. 401-403) by taking profit sharing as given and by assuming that the union is utilitarian. Therefore, the objective function of the monopoly labor union is assumed to be $V=v L+(N-L) \bar{v}$. By using the equations (5a) and (5b) the unions' calculus is to maximize the surplus anticipating domestic labor demand (3a), outsourcing demand (3b) and effort function (7) according to

$$
\max _{w} V=(w-g(\bar{e})-b) L+\tau \pi+b N,
$$

where $b$ is the exogenous minimum income for the labor union members $N$.

Solving problem (9), we get as the first-order condition

$$
V_{w}=\frac{L}{w}\left[\frac{d L}{d w} \frac{w}{L}(w-b-g(\bar{e}))+\tau \frac{d \pi}{d w} \frac{w}{L}+w\left(1-\frac{d g(\bar{e})}{d w}\right)\right]=0,
$$

where the overall wage effect on the profit, includes the direct wage effect and the indirect effect via effort, so that $\frac{d \pi}{d w}=-(1-\phi) \cdot L<0$ when $\phi<1$. Using this and $\frac{d g(\bar{e})}{d w}=\frac{\bar{e}^{1 / \gamma} \cdot \phi}{w}$ as well as the total wage elasticity of labor $\eta=\frac{\gamma+(1-\gamma) \cdot \eta_{w}}{1+\gamma \cdot\left(\eta_{w}-1\right)}$ (see Appendix A), the first-order condition (10) can be solved to

$$
w=\frac{\eta b+\bar{e}^{1 / \gamma}(\eta \gamma-\phi)}{\eta-1+\tau(1-\phi)} .
$$

From equation (11) one can see that profit sharing affects the wage in different ways. The first working channel is the direct effect, which can be seen in the 
denominator of (11), while the second is an indirect effect via the total wage elasticity $\eta$ and via effort $\bar{e}$, respectively via the wage elasticity of effort $\phi$.

Starting with the direct effect $\tau \cdot(1-\phi)$, we see that this one can be distinguished into two working mechnism. The first part of the term $\tau-\tau \phi$ describes the pure substitution effect. Since a higher wage will decrease profit and therefore profit income, it increases the resulting utility loss of a wage increase for the union respectively its members. Due to this increasing effect on the union's marginal costs, higher profit sharing will induce a less aggressive wage setting. Therefore, this effect will decrease the base wage, which means that a former part of the base wage is substituted by profit income. However, the wage decrease also affects the effort. Thus, the second part of the term describes a feedback effect via the wage elasticity of effort. Due to our assumption $\phi<1$ we see, that the direct effect dominates and profit sharing will lead to wage moderation.

The indirect working channel of profit sharing is characterized by the effect on the labor demand elasticity $\eta$, effort $e$ and wage elasticity of effort $\phi$. We know that higher profit sharing increases effort and thus productivity. Intuitively, the higher productivity will be compensated by a higher wage level, which can also be seen from equation (11). Another indirect impact results from the effect on the wage elasticity of the labor demand. As pointed out in Appendix A, higher profit sharing makes the labor demand less elastic, i.e. $\frac{d \eta}{d \tau}<0$. Since profit sharing increases effort and induces a higher labor demand, the utility loss of the union concerning a higher wage decreases, which lead to a more aggressive union and a higher wage level. While the effort and labor demand elasticity effects raise the wage, the effect via the wage elasticity of effort is ambiguous. Using equation (8) we find that $\frac{d \phi}{d \tau}<0$. As one can see from (11), higher profit sharing will have a wage increasing effect (numerator) but also a wage decreasing effect (denominator) via the wage elasticity of effort.

This verbal description shows that profit sharing via the direct effect has a wage moderation impact while it affects the wage via the indirect effect in an ambiguous way. Even, if we assume that the impacts of profit sharing via the indirect effect are working in the same directions and increase the wage, the direct and indirect working channel are opposed effects. Thus, a priori we cannot identify the overall impact of profit sharing on base wage.

Due to the difficulty to derive the wage effect of profit sharing from an intuitively point of view, we now turn to a detailed mathematical analysis. Using 
our former results concerning effort and wage elasticity of effort respectively labor demand, we can rewrite equation (11) as

$$
w=\frac{\gamma+(1-\gamma) \cdot \eta_{w}}{\left(\eta_{w}-1\right)\left(1-2 \gamma+\frac{\tau \gamma^{2}}{L}\right)+\tau \cdot\left(1-2 \gamma+\frac{\gamma}{L}\right)} b=A(c, w, \tau) \cdot b
$$

It should be emphasized that (11a) is an implicit formulation, as both the numerator and denominator in the mark-up factor $A(c, w, \tau)$ depend on wage $w$ in a non-linear way via labor demand and direct wage elasticity of labor demand.

The implicit differentiation of (11a) with respect to profit sharing gives $\frac{d w}{d \tau}=\frac{A_{\tau} b}{1-A_{w} b}$ and by substituting $b=w / A$, we can characterize this as

$$
\frac{d w}{d \tau}=\frac{\frac{A_{\tau} w}{A}}{1-\frac{A_{w} w}{A}},
$$

where $1-\frac{A_{w} w}{A}>0$ under the assumption $\tau\left[1-\gamma\left(1-\frac{1}{L}\right)\right] \leq 1$ (see Appendix B).

In terms of profit sharing in Appendix B, we point out that there are two effects which influence the term $\frac{A_{\tau} w}{A}$. While the first impact is positive under the assumption that $\tau\left[1-\gamma\left(1-\frac{1}{L}\right)\right] \leq 1$, the second impact will be negative if the profit share elasticity of labor demand is smaller than one, i.e. $\frac{d L}{d \tau} \frac{\tau}{L}<1$. Therefore, under these assumptions, the effect of profit sharing on the wage is a priori ambiguous, which means that $\frac{A_{\tau} w}{A}=$ ? if $\phi<1$.

We can summarize our findings as follows. ${ }^{14}$

14 One can also show in this model that lower cost of outsourcing decreases wage under the assumption that $\tau\left[1-\gamma\left(1-\frac{1}{L}\right)\right]<1$. Lower outsourcing cost means for given wage level a higher outsourcing demand and a more elastic labor demand. Thus the opportunity for the labor union to set higher wages falls. This lies in conformity with empirics concerning evidence from various countries, e.g. Feenstra and Hanson (1999), Hijzen et al. (2005), Hsieh and Woo (2005), Egger and Egger (2006), Geishecker and Görg (2008) and Munch and Skaksen (2009). 
Proposition 2: In the presence of flexible outsourcing when the wage elasticity of effort and the profit share elasticity of labor demand are smaller than one, profit sharing has an ambiguous effect on the base wage and therefore a compensatory or supplementary character.

However, we can also analyze the impact of profit sharing on wage for the special case $\gamma=1 / 2$, where the wage elasticity of effort is one, i.e. $\phi=1$. In this case, as shown in Appendix B, the effect of profit sharing can be expressed as

$$
\left.\frac{d w}{d \tau}\right|_{\phi=1}=\frac{1}{2} \frac{w}{\tau}\left(\left.\frac{d L}{d \tau} \frac{\tau}{L}\right|_{\phi=1}-1\right)<0
$$

where $\left.\frac{d L}{d \tau} \frac{\tau}{L}\right|_{\phi=1}=\frac{\eta_{w}-1}{\eta_{w}+1} \in(0 ; 1)$

We can summarize this finding as

Corollary 1: When the base wage elasticity of effort is one, profit sharing has a negative effect on the base wage and therefore a compensatory character.

Our analysis shows that profit sharing has in general a supplementary or complementary character, while in the special case $\phi=1$, we found that profit sharing lowers the bargained wage and thus it is a compensatory income part. ${ }^{15}$

Using the wage effects, we can demonstrate the effects of profit sharing on outsourcing and employment in the general case $\phi<1$ and the special case $\phi=1$.

We can write the working channel of profit sharing on outsourcing as $\frac{d M}{d \tau}=\frac{\partial M}{\partial \bar{e}} \cdot \frac{d \bar{e}}{d \tau}+\frac{d M}{d w} \cdot \frac{d w}{d \tau}$ where $\frac{d \bar{e}}{d \tau}>0, \frac{\partial M}{\partial \bar{e}}<0$ and $\frac{d M}{d w}=\frac{\partial M}{\partial w}+\frac{\partial M}{\partial \bar{e}} \frac{d \bar{e}}{d w}>0$.

Using the former results, we have in the general case (for a detailed analysis see Apendix B)

$$
\frac{d M}{d \tau}=\underbrace{\frac{\partial M}{\partial \bar{e}} \cdot \frac{d \bar{e}}{d \tau}}_{-}+\underbrace{\frac{d M}{d w}}_{+} \cdot \underbrace{\frac{d w}{d \tau}}_{?}=?
$$

15 There is also some empirical evidence for both properties. Black and Lynch (2000) show by using U.S. data, that profit sharing results in lower regular pay for workers, what implies a compensatory character, but in Wadhwani and Wall (1990) by using UK data and also in Kraft and Ugarkovic (2005) by using German panel data it has been shown that introducing profit sharing do not reduce the wage, what implies a supplementary character. 
For the special case $\phi=1$ we get for the impact of profit sharing on outsourcing an unambiguous result, since now the wage effect can be determined. Thus we have in that case

$$
\left.\frac{d M}{d \tau}\right|_{\phi=1}=\underbrace{\frac{\partial M}{\partial \bar{e}} \cdot \frac{d \bar{e}}{d \tau}}_{-}+\underbrace{\frac{d M}{d w}}_{+} \cdot \underbrace{\left.\frac{d w}{d \tau}\right|_{\phi=1}}_{-}<0 .
$$

In a similar way, one can also analyze the effect of committed profit sharing on employment. The employment impact can be formalized as $\frac{d L}{d \tau}=\frac{\partial L}{\partial \bar{e}} \cdot \frac{d \bar{e}}{d \tau}+\frac{d L}{d w} \cdot \frac{d w}{d \tau}$, where $\frac{d \bar{e}}{d \tau}>0$ and $\frac{d L}{d w}=\frac{\partial L}{\partial w}+\frac{\partial L}{\partial \bar{e}} \frac{d \bar{e}}{d w}<0$. Thus, we have in the general case

$$
\frac{d L}{d \tau}=\underbrace{\frac{\partial L}{\partial \bar{e}} \cdot \frac{d \bar{e}}{d \tau}}_{+}+\underbrace{\frac{d L}{d w}}_{-} \cdot \underbrace{\frac{d w}{d \tau}}_{?}=?
$$

For the special case, when the wage elasticity of effort is one, we have

$$
\left.\frac{d L}{d \tau}\right|_{\phi=1}=\underbrace{\frac{\partial L}{\partial \bar{e}} \cdot \frac{d \bar{e}}{d \tau}}_{+}+\underbrace{\frac{d L}{d w}}_{-} \cdot \underbrace{\left.\frac{d w}{d \tau}\right|_{\phi=1}}_{-}>0 .
$$

We can now summarize these findings as

Proposition 3: The effect of profit sharing on flexible outsourcing and domestic employment is

(a) ambiguous, when the wage elasticity of effort and the profit share elasticity of labor demand are smaller than one, but

(b) unambiguous negative on outsourcing and positive on employment, when the wage elasticity of effort is one.

Implementing profit sharing will affect the wage and therefore domestic labor demand and outsourcing. Since the wage effect of profit sharing is in the general case ambiguous, also the wage induced demand reactions are ambiguous. However, there is also a productivity effect due to effort. Since profit sharing increases effort, this leads to an increasing labor demand and some outsourcing activities will be 
avoided. For our special case, we could show that due to the compensatory character of profit sharing, the wage effect and productivity effect are working in the same directions and lead to a higher domestic labor demand and lower outsourcing. Notice that this can also happen in the general case even if profit sharing leads to a higher wage. In that case, the wage effect will be dominated by the productivity effect.

\section{III.2. Optimal Committed Profit Sharing}

On this stage, we close the model and concentrate on the optimal profit share. At this point, we have to refer to Koskela and König (2010) to make clear the central difference to this paper. While in Koskela and König (2010) there is a central effort determination by the labor union, here we model an individual effort determination. Resulting from this modeling, we find that in the case of individual effort determination the wage increases worker's productivity, while in the case of a central effort setting the productivity is unaffected by profit sharing. For the optimal profit share, Koskela and König (2010) show, that although profit sharing lowers the base wage, a profit maximizing firm will abstain from such a compensation scheme. Therefore, the question we elaborate is, if the firm will implement a profit sharing scheme, when the base wage effect is complemented by an increase effort respectively labor productivity?

The problem of the firm is (see Appendix $\mathrm{C}$ for the detailed calculation)

$$
\max _{\tau} \bar{\pi}=(1-\tau) \cdot \pi^{*}=(1-\tau) \cdot[F-w L-c M]
$$

subject to the domestic labor and outsourcing demand, effort and base wage.

From (18) we get the first-order condition $-\pi^{*}+(1-\tau) \frac{d \pi^{*}}{d \tau}=0$, where the profit effect of profit sharing can be calculated as $\frac{d \pi^{*}}{d \tau}=\frac{w \cdot L}{\tau} \cdot\left[\mu-(1-\phi) \cdot \frac{d w}{d \tau} \frac{\tau}{w}\right]$. Using $\frac{\pi^{*}}{L}=\frac{w}{s} \frac{1-\alpha}{\alpha}$, the optimal committed profit share is implicit given by

$$
\frac{1-\tau}{\tau} \cdot\left[\mu-(1-\phi) \cdot \frac{d w}{d \tau} \frac{\tau}{w}\right]=\underbrace{\frac{1-\alpha}{s \cdot \alpha}}_{+},
$$

where $\mu$ is the effort elasticity in terms of profit sharing, $\phi$ is the wage elasticity of effort and $s$ is the cost share of domestic labor. Since we assume that domestic 
labor and outsourcing are not perfect substitutes, we have $0<s<1$, which means that the RHS of (19) is definitively positive.

To answer our research question and show if the firm will implement a profit sharing scheme or not, we have to analyze the sign of the LHS, respectively the term in brackets.

From the former analysis we know that $\mu>0$ and $0<\phi<1$. Therefore the sign and the size of the profit share elasticity of the base wage determine the sign of the term in brackets. For a detailed analysis, we can distinguish two cases i) profit sharing decreases the wage and ii) profit sharing increases the wage.

i) profit sharing decreases the wage

This case implies that profit sharing has a compensatory character, since the reduced wage income will be compensated by profit income. Formally, this means that the profit share elasticity of the base wage is negative, i.e. $\frac{d w}{d \tau} \frac{\tau}{w}<0$. Since profit sharing decreases the wage and increases the productivity at the same time, the firm owner gains if such a scheme will be implemented. One can see this in equation (19), where the term in brackets is positive for $\frac{d w}{d \tau} \frac{\tau}{w}<0$. Therefore, to fulfill equation (19) the term $\frac{1-\tau}{\tau}$ has to be positive, which is only true for $\tau>0$.

ii) profit sharing increases the wage

In contrast to the argumentation above, since profit sharing increases the base wage, i.e. $\frac{d w}{d \tau} \frac{\tau}{w}>0$, only the effort increasing effect favored the implementation of a profit sharing scheme from the firm perspective. However, if the productivity effect dominates the wage effect, the loss of higher wage costs will be compensated by higher productivity. Therefore, it is still beneficial for the firm to implement a profit sharing scheme. Algebraically this is also shown in (19), where a dominating productivity effect is characterized by $\mu>(1-\phi) \cdot \frac{d w}{d \tau} \frac{\tau}{w}$, which means that the term in brackets is positive. To fulfill the first order condition also $\frac{1-\tau}{\tau}$ has to be positive, which gives $\tau>0$.

If the productivity effect doesn't overweight the wage effect, i.e. $\mu<(1-\phi) \cdot \frac{d w}{d \tau} \frac{\tau}{w}$, the firm owner desists from profit sharing, since the costs of an implementation of such a scheme are higher than the gains by increasing the productivity. Concerning 
equation (19) this results because under $\mu<(1-\phi) \cdot \frac{d w}{d \tau} \frac{\tau}{w}$ the term in brackets becomes negative. Since the RHS of (19) is positive the condition is only fulfill for $\frac{1-\tau}{\tau}<0$. As one can see, this holds for $\tau<0$. Since implementing a negative profit share is impossible, we obtain a corner solution, where the firm desists from profit sharing. In that case the firm owner remains the overall profit. Of course, $\frac{1-\tau}{\tau}<0$ also holds for $\tau>1$, which means that the workforce receive the overall profit, while the firm owner has no income. However, under the assumption of $\pi^{*}>0$, this is no option for the firm owner, since in the case of $\tau=0$ he can realize this profit.

Proposition 4: For individual effort provision, the firm will optimally implement a profit sharing scheme,

(a) if profit sharing has a compensatory character and

(b) if profit sharing has a supplementary character, but the productivity effect exceed the wage effect.

Similar to the analyze above, we also determine the optimal profit share for the special case of $\phi=1$. Since we know that $\left.\frac{d w}{d \tau} \frac{\tau}{w}\right|_{\phi=1}>0$, the firm will implement such a compensation scheme. In that case, from equation (19) we yield for the optimal profit share

$$
\left.\tau\right|_{\phi=1}=\frac{\left.s \cdot \alpha \cdot \mu\right|_{\phi=1}}{(1-\alpha)+\left.s \cdot \alpha \cdot \mu\right|_{\phi=1}} \in(0 ; 1) .
$$

Corollary 2: When the base wage elasticity of effort is one, the firm will implement a profit sharing scheme.

The analysis above shows that under an individual effort determination the firm will induce higher productivity with the implementation of profit sharing, while in Koskela and König (2010) the effort is constant.

However, profit sharing can affect the wage, which also has an impact on the decision to implement a profit sharing scheme. In Koskela and König (2010) it is shown that although profit sharing lowers the base wage, a profit maximizing firm will abstain from profit sharing, since the wage reduction realized by the union is 
lower than the needed wage reduction by the firm. As our analysis shows under a positive effort effect of profit sharing in case of wage moderation the firm will implement such a compensation scheme. Further it was shown that also in the case of a supplementary character this kind of compensation scheme will be implemented if the induced productivity effect dominates the wage increasing effect. Thus, the difference of effort determination respectively existence of a productivity effect is crucial for the decision to implement a remuneration scheme with profit sharing.

\section{Conclusions}

In the public debate, outsourcing is associated with less employment, since it is cheaper. To work against this threat, the domestic wages has to decline. However, this results in an income loss. To solve this puzzle, an alternative compensation scheme with profit sharing can be implemented, since it can positive affect the productivity and decrease wage without lowering the income of the workers. If labor markets are imperfect since a union set the wage, we have analyzed the questions: First, how does the implementation of profit sharing affect effort and thus productivity? Second, how does profit sharing influence the bargained wage and thus outsourcing demand? Third, will the firm implement a profit sharing scheme, if workers decide individually about effort provision?

We have found the intuitive result that profit sharing and the wage level have an individual effort-augmenting effect and therefore increase productivity. This is due to the fact that higher profit sharing sets an incentive to increase the working effort to realize more profit and therefore to increase the income. Concerning our second question, we demonstrate that the wage effect of profit sharing in general is ambiguous. On the one hand, there is a wage decreasing substitution effect, but on the other hand, there is a wage increasing effect via labor demand elasticity and effort. Therefore, the outsourcing and employment effect is also ambiguous. Since the labor demand effect consist of a productivity effect and a wage effect, domestic employment can increase even if profit sharing leads to a higher wage. If the wage will decline, the employment effect will be definitively positive. Regarding our third question, we find that there will be a firm's optimal committed profit sharing under individual effort determination, if profit sharing has a compensatory character, i.e. the wage declines. Also, if profit sharing has a supplementary character, i.e. the wage increases, there can be such a compensation scheme. However, in that case the productivity effect has to dominate the wage effect. This result shows that the effort determination and therefore the productivity effect is 
decisive to implement an alternative compensation scheme with profit sharing, where the income is uncoupled from the wage.

\section{Appendix A: total and direct own wage elasticities}

The first-order conditions of equation (2) can be expressed as $w=F_{L}=\alpha \cdot \bar{e}^{\frac{\sigma-1}{\sigma}} \cdot F^{1-\frac{\sigma-1}{\alpha \sigma}} \cdot L^{-\frac{1}{\sigma}}$ and $c=F_{M}=\alpha \cdot F^{1-\frac{\sigma-1}{\alpha \sigma}} \cdot M^{-\frac{1}{\sigma}}$. For the cross derivatives we obtain $\quad F_{L M}=\alpha \cdot \bar{e}^{\frac{\sigma-1}{\sigma}} \cdot F^{-\frac{\sigma-1}{\alpha \sigma}} \cdot L^{-\frac{1}{\sigma}} \cdot F_{M} \cdot\left(1-\frac{\sigma-1}{\alpha \sigma}\right) \quad$ and $F_{M L}=\alpha \cdot \bar{e}^{\frac{\sigma-1}{\sigma}} \cdot F^{-\frac{\sigma-1}{\alpha \sigma}} \cdot M^{-\frac{1}{\sigma}} \cdot F_{L} \cdot\left(1-\frac{\sigma-1}{\alpha \sigma}\right)$, where $F_{L}>0$ and $F_{M}>0$. Since under the assumption of substitutionality of the inputs $F_{L M}<0$ and $F_{M L}<0$ has to hold, we have to assume that $1-\frac{\sigma-1}{\alpha \sigma}<0$, which lead to $\sigma>\frac{1}{1-\alpha}$.

Using (3a) and (3b) we can solve for the cost function by substituting the conditional demand system ( $3 \mathrm{a})$ and ( $3 \mathrm{~b})$ in $K=w L+c M$. As the cost function we obtain

$$
K=\left((w / \bar{e})^{1-\sigma}+c^{1-\sigma}\right)^{\frac{\sigma}{\sigma-1}} \cdot F^{\frac{1}{\alpha}}=k \cdot F^{\frac{1}{\alpha}} .
$$

Thus the cost share of labour and outsourcing can be expressed as

$$
s=\frac{w L}{k \cdot F^{\frac{1}{\alpha}}}=\frac{(w / \bar{e})^{1-\sigma}}{(w / \bar{e})^{1-\sigma}+c^{1-\sigma}}, 1-s=\frac{c M}{k \cdot F^{\frac{1}{\alpha}}}=\frac{c^{1-\sigma}}{(w / \bar{e})^{1-\sigma}+c^{1-\sigma}} .
$$

For the wage impact on labour demand, we use (3a). The derivative of concerning the wage, $\frac{\partial L}{\partial w}=L$, can be formulated as

$$
\begin{aligned}
& L_{w}=\frac{1}{\alpha} F^{\frac{1}{\alpha}-1} \frac{F_{w}}{w} \cdot\left((w / \bar{e})^{1-\sigma}+c^{1-\sigma}\right)^{\frac{\sigma}{\sigma-1}} \cdot(w / \bar{e})^{1-\sigma} \\
& +F^{\frac{1}{\alpha}} \frac{\sigma}{w} \cdot\left((w / \bar{e})^{1-\sigma}+c^{1-\sigma}\right)^{\frac{\sigma}{\sigma-1}}-1\left(\frac{w}{\bar{e}}\right)^{1-\sigma} \cdot w^{-\sigma} \bar{e}^{\sigma-1}-F^{\frac{1}{\alpha}} \cdot\left((w / \bar{e})^{1-\sigma}+c^{1-\sigma}\right)^{\frac{\sigma}{\sigma-1}} \cdot \sigma \cdot\left(\frac{w}{\bar{e}}\right)^{1-\sigma} .
\end{aligned}
$$

Substituting (3a) and (A2), this expression can be simplified to

$$
L_{w}=\frac{1}{\alpha} \frac{L}{Y} F_{w}+\frac{\sigma}{w} \cdot s L-\frac{\sigma}{w} \cdot L .
$$

Rewritten the profit function to $\pi=F-K$ the first order condition for a profit maximum $1=\frac{k}{\alpha} F^{\frac{1-\alpha}{\alpha}}$ can be solved to $F=\alpha^{\frac{\alpha}{1-\alpha}} k^{-\frac{\alpha}{1-\alpha}}$, which gives $F_{w}=-\frac{\alpha}{1-\alpha} \frac{s}{w} F$. Inserting this in (A3) we get

$$
L_{w}=\frac{L}{w}\left(-\frac{s}{1-\alpha}+\sigma(s-1)\right)<0 .
$$


In a similar way, we obtain

$$
\begin{aligned}
& \frac{\partial L}{\partial \bar{e}}=L_{\bar{e}}=? ?, \\
& \frac{\partial M}{\partial w}=M_{w}=\frac{s}{w} \cdot M \cdot\left[\sigma-\frac{1}{1-\alpha}\right]>0, \\
& \frac{\partial M}{\partial \bar{e}}=M_{\bar{e}}=-\frac{s}{\bar{e}} \cdot M \cdot\left[\sigma-\frac{1}{1-\alpha}\right]<0 .
\end{aligned}
$$

Analogously, we have $L_{c}>0$ and $M_{c}<0$.

From (A4) one can determine the labour demand elasticity

$$
\eta_{w}=-\frac{L_{w} \cdot w}{L}=-\frac{s}{1-\alpha}+\sigma(s-1)=\sigma(1-s)+\frac{s}{1-\alpha} .
$$

The effect of the wage rate on the direct own wage elasticity taking into account the impact on effort can be expressed as

$$
\frac{\partial \eta_{w}}{\partial w}=s_{w} \cdot\left(\frac{1}{1-\alpha}-\sigma\right)>0
$$

where $s_{w}=\frac{s}{w}(1-\sigma)(1-s)(1-\phi)<0$ since we assume $\phi<1$ and $\sigma>\frac{1}{1-\alpha}$.

The effect of profit sharing on the direct own wage elasticity taking into account the impact on effort can be expressed as

$$
\frac{\partial \eta_{w}}{\partial \tau}=s_{\tau} \cdot\left(\frac{1}{1-\alpha}-\sigma\right)<0
$$

where $s_{\tau}=-\frac{s}{e}(1-\sigma)(1-s) \frac{d \bar{e}}{d \tau}<0$.

Since, the base wage $w$ affects total labor demand in two ways, we can separate the total elasticity into a direct labor demand effect and an indirect effect via effort: $\eta=-\frac{d L}{d w} \frac{w}{L}=-\left(\frac{\partial L}{\partial w} \frac{w}{L}+\frac{\partial L}{\partial \bar{e}} \frac{\bar{e}}{L} \cdot \frac{w}{\bar{e}} \frac{d \bar{e}}{d w}\right)$, where $-\frac{\partial L}{\partial w} \frac{w}{L}=\eta_{w}, \quad \frac{\partial L}{\partial \bar{e}} \frac{\bar{e}}{L}=\eta_{w}-1$ and $\frac{d \bar{e}}{d w} \frac{w}{\bar{e}}=\phi$, so that we can rewrite the total wage elasticity as

$$
\eta=-\frac{d L}{d w} \frac{w}{L}=\eta_{w}(1-\phi)+\phi=\frac{\gamma+(1-\gamma) \eta_{w}}{1-\gamma+\gamma \eta_{w}} .
$$

The total wage elasticity can be presented in terms of direct wage elasticity as

$$
\frac{\partial \eta}{\partial \eta_{w}}=\frac{1-2 \gamma}{\left(1-\gamma+\gamma \eta_{w}\right)^{2}}>0 \text { as } \gamma<\frac{1}{2},
$$

so that there is a positive relationship between the total wage elasticity and the direct own wage elasticity in the case $\gamma<1 / 2$.

Therefore, in terms of total wage elasticity of labor demand, when the wage elasticity of effort is smaller than one, $\phi<1$, a higher wage increases the total wage 
elasticity of labor demand $\frac{d \eta}{d w}=\frac{\partial \eta}{\partial \eta_{w}} \cdot \frac{\partial \eta_{w}}{\partial w}>0$, while higher profit sharing decreases it $\frac{d \eta}{d \tau}=\frac{\partial \eta}{\partial \eta_{w}} \cdot \frac{\partial \eta_{w}}{\partial \tau}<0$.

Writing the profit as $\pi=F-k \cdot F^{\frac{1}{\alpha}}$, with $k=\left((w / \bar{e})^{1-\sigma}+c^{1-\sigma}\right)^{\frac{\sigma}{\sigma-1}}$, one obtain as the optimal output $F=\alpha^{\frac{\alpha}{1-\alpha}} \cdot k^{\frac{-\alpha}{1-\alpha}}$. Using this, the direct profit effect of individual effort $\frac{\partial \pi}{\partial e}=\frac{\partial\left(F-k \cdot F^{\frac{1}{\alpha}}\right)}{\partial \bar{e}} \cdot \frac{\partial \bar{e}}{\partial e}=\left[\frac{\partial F}{\partial \bar{e}}-\frac{\partial k}{\partial \bar{e}} \cdot F^{\frac{1}{\alpha}}-k \cdot F^{\frac{1-\alpha}{\alpha}} \cdot \frac{\partial F}{\partial \bar{e}}\right] \cdot \frac{\partial \bar{e}}{\partial e}$ can be solved to $\frac{\partial \pi}{\partial e}=-\frac{\partial k}{\partial \bar{e}} \cdot F^{\frac{1}{\alpha}} \cdot \frac{\partial \bar{e}}{\partial e}$. In combination with the conditional labor demand (3a), and $\frac{\partial \bar{e}}{\partial e}=\frac{1}{L}$ this gives $\frac{\partial \pi}{\partial e}=\frac{w}{\bar{e}}$. The direct wage effect $\frac{\partial \pi}{\partial w}=\frac{\partial(F-K)}{\partial w}$, where $K=k \cdot F^{\frac{1}{\alpha}}$ characterize the total costs. Thus, we have $\frac{\partial \pi}{\partial w}=\frac{\partial F}{\partial w}-\frac{\partial K}{\partial F} \cdot \frac{\partial F}{\partial w}-\frac{\partial K}{\partial w}$, where the first order condition of profit maximization is $\frac{\partial F}{\partial w}-\frac{\partial K}{\partial w} \cdot \frac{\partial F}{\partial w}=0$. Finally we have under using Hotelling's lemma, i.e. $\frac{\partial K}{\partial w}=L$, which yield $\frac{\partial \pi}{\partial w}=-L$. Taking into account the effort reaction, the overall wage effect on profit is $\frac{d \pi}{d w}=\frac{\partial \pi}{\partial w}+\frac{\partial \pi}{\partial \bar{e}} \frac{d \bar{e}}{d w}$, which gives $\frac{d \pi}{d w}=-L+L \cdot \frac{w}{\bar{e}} \frac{d \bar{e}}{d w}=-(1-\phi) \cdot L$.

\section{Appendix B: wage effect of profit sharing}

We find that the wage is a mark-up on the outside option. The mark-up $A=\left(\gamma+(1-\gamma) \eta_{w}\right) / X$, where $X=\left(\eta_{w}-1\right)\left(1-2 \gamma+\frac{\tau \gamma^{2}}{L}\right)+\tau\left(1-2 \gamma+\frac{\gamma}{L}\right), \quad$ is a implicit formulation, where the effect of wage on the mark-up can be expressed as $A_{w}=X^{-2}\left[X(1-\gamma) \frac{\partial \eta_{w}}{\partial w}-\left(\gamma+(1-\gamma) \eta_{w}\right) \frac{\partial X}{\partial w}\right]$ so that
$\frac{A_{w} w}{A}=\frac{w\left[X(1-\gamma) \frac{\partial \eta_{w}}{\partial w}-\left(\gamma+(1-\gamma) \cdot \eta_{w}\right) \frac{\partial X}{\partial w}\right]}{X\left(\gamma+(1-\gamma) \eta_{w}\right)}$

where $\frac{\partial \eta_{w}}{\partial w} w>0$ as seen from equation (A6). The wage effect on the $X$-term is $\frac{\partial X}{\partial w} w=\left(1-2 \gamma+\frac{\tau \gamma^{2}}{L}\right) \frac{\partial \eta_{w}}{\partial w} w+\left(\eta_{w}-1\right) \frac{\tau \gamma^{2}}{L}\left(-\frac{d L}{d w} \frac{w}{L}\right)+\frac{\tau \gamma}{L}\left(-\frac{d L}{d w} \frac{w}{L}\right)$, which can be rewritten as 


$$
\frac{\partial X}{\partial w} w=\left(1-2 \gamma+\frac{\tau \gamma^{2}}{L}\right) \frac{\partial \eta_{w}}{\partial w} w+\left[\frac{\gamma+(1-\gamma) \cdot \eta_{w}}{1+\gamma \cdot\left(\eta_{w}-1\right)}\right]\left[\left(\eta_{w}-1\right) \gamma+1\right] \frac{\tau \gamma}{L}>0 \text { as } \phi \leq 1
$$

Using (B2) and $Y=X\left(\gamma+(1-\gamma) \cdot \eta_{w}\right)$, we can express (B1) as

$$
\frac{A_{w} w}{A}=Y^{-1}\left(\frac{\partial \eta_{w}}{\partial w} w\left[(1-2 \gamma)\left[\tau\left(1-\gamma\left(1-\frac{1}{L}\right)\right)-1\right]\right]-\left[\left(\gamma+(1-\gamma) \cdot \eta_{w}\right)\right]^{2} \frac{\tau \gamma}{L}\right)<0
$$

since $\frac{\partial \eta_{w}}{\partial w}>0$ if $\phi<1$ and $\tau\left[1-\gamma\left(1-\frac{1}{L}\right)\right] \leq 1$. In this case, we have $1-\frac{A_{w} w}{A}>0$.

Finally, the effect of profit sharing on the mark-up can be expressed by using $A_{\tau}=X^{-2}\left[X(1-\gamma) \frac{\partial \eta_{w}}{\partial \tau}-\left(\gamma+(1-\gamma) \cdot \eta_{w}\right) \frac{\partial X}{\partial \tau}\right]$ so that we have

$$
\frac{A_{\tau} w}{A}=\frac{w\left[X(1-\gamma) \frac{\partial \eta_{w}}{\partial \tau}-\left(\gamma+(1-\gamma) \eta_{w}\right) \frac{\partial X}{\partial \tau}\right]}{X\left(\gamma+(1-\gamma) \eta_{w}\right)}
$$

where $\frac{\partial \eta_{w}}{\partial \tau}<0$ as seen in (A7). The effect of profit sharing on the $X$-term is $\frac{\partial X}{\partial \tau}=\left(1-2 \gamma+\frac{\tau \gamma^{2}}{L}\right) \frac{\partial \eta_{w}}{\partial \tau}-\left(\left(\eta_{w}-1\right) \gamma+1\right) \frac{\gamma}{L} \cdot \frac{d L}{d \tau} \frac{\tau}{L}+1-2 \gamma+\left(\left(\eta_{w}-1\right) \gamma+1\right) \frac{\gamma}{L}$, where $\frac{d L}{d \tau}=\frac{\partial L}{\partial \bar{e}} \frac{d \bar{e}}{d \tau}$, which can be solved to

$$
\frac{d L}{d \tau} \frac{\tau}{L}=\frac{\partial L}{\partial \bar{e}} \frac{\bar{e}}{L} \cdot \frac{d \bar{e}}{d \tau} \frac{\tau}{\bar{e}}=\eta_{\bar{e}} \cdot \mu=\left(\eta_{w}-1\right) \cdot \mu>0
$$

Using this, (B4) can be written as

$$
\frac{A_{\tau} w}{A}=Y^{-1} w\left(\begin{array}{l}
\frac{\partial \eta_{w}}{\partial \tau}\left[(1-2 \gamma)\left[\tau\left(1-\gamma\left(1-\frac{1}{L}\right)\right)-1\right]\right] \\
\left.+\left(\gamma+(1-\gamma) \eta_{w}\right)\left[\left(\eta_{w}-1\right) \gamma+1\right] \cdot\left(\frac{d L}{d \tau} \frac{\tau}{L}-1\right) \cdot \frac{\gamma}{L}-(1-2 \gamma)\right]
\end{array}\right),(
$$

where the first term is positive under the assumptions $\tau\left[1-\gamma\left(1-\frac{1}{L}\right)\right]<1$ and $\gamma<1 / 2$ since $\frac{\partial \eta_{w}}{\partial \tau}<0$. If the elasticity of labor demand in terms of profit sharing is $\frac{d L}{d \tau} \frac{\tau}{L}<1$, the second term is negative. Consequently under these assumptions, the effect of profit sharing on the mark-up and on the wage is a priori ambiguous, i.e. $\frac{A_{\tau} w}{A}=$ ? and $\frac{d w}{d \tau}=$ ? .

For the special case $\gamma=1 / 2$ respectively $\phi=1$ equation (B3) can be simplified to $\frac{A_{w} w}{A}=\frac{-\left[\left(\gamma+(1-\gamma) \cdot \eta_{w}\right)\right]}{\left(\eta_{w}-1\right) \cdot \gamma+1}=-1$, while (B6) becomes $\frac{A_{\tau} w}{A}=\frac{w}{\tau}\left(\left.\frac{d L}{d \tau} \frac{\tau}{L}\right|_{\phi=1}-1\right)$ with 
$\left.\frac{d L}{d \tau} \frac{\tau}{L}\right|_{\phi=1}=\frac{\eta_{w}-1}{\eta_{w}+1} \in(0 ; 1)$. Using these expressions the wage effect of profit sharing is $\left.\frac{d w}{d \tau}\right|_{\phi=1}=\frac{1}{2} \frac{w}{\tau}\left(\left.\frac{d L}{d \tau} \frac{\tau}{L}\right|_{\phi=1}-1\right)<0$, which corresponds to equation (13).

The effect on the outsourcing demand is $\frac{d M}{d \tau}=\frac{\partial M}{\partial \bar{e}} \frac{d \bar{e}}{d \tau}+\frac{d M}{d w} \frac{d w}{d \tau}$, where $\frac{d M}{d w}=\frac{\partial M}{\partial w}+\frac{\partial M}{\partial \bar{e}} \frac{d \bar{e}}{d \tau}$. Using (A4b) and (A4c) the effect on outsourcing can be written as

$$
\frac{d M}{d \tau}=\frac{M}{\tau} \cdot s \cdot \underbrace{\left(\sigma-\frac{1}{1-\alpha}\right)}_{+} \cdot[\underbrace{(1-\mu)}_{+} \cdot \underbrace{\frac{d w}{d \tau} \frac{\tau}{w}}_{?}-\underbrace{\mu}_{+}]=? .
$$

The effect on the outsourcing demand is $\frac{d L}{d \tau}=\frac{\partial L}{\partial \bar{e}} \frac{d \bar{e}}{d \tau}+\frac{d L}{d w} \frac{d w}{d \tau}$, which can be rewritten to

$$
\frac{d L}{d \tau}=\frac{L}{\tau}[\underbrace{\eta_{\bar{e}}}_{+} \cdot \underbrace{\frac{d \bar{e}}{d \tau} \frac{\tau}{\bar{e}}}_{+}-\underbrace{\eta}_{+} \cdot \underbrace{\frac{d w}{d \tau} \frac{\tau}{w}}_{?}]=? .
$$

\section{Appendix C: Effect of profit sharing on indirect profit}

Differentiating the indirect profit $\pi^{*}$ in terms of $\tau$ gives $\frac{d \pi^{*}}{d \tau}=\frac{d \pi^{*}}{d w} \frac{d w}{d \tau}+\frac{\partial \pi^{*}}{\partial \bar{e}} \frac{d \bar{e}}{d \tau}$. Using the results of Appendix A, we can rewrite the profit effect to

$$
\frac{d \pi^{*}}{d \tau}=L \cdot\left[\frac{w}{\bar{e}} \frac{d \bar{e}}{d \tau}-(1-\phi) \frac{d w}{d \tau}\right]
$$

The first order condition $-\pi^{*}+(1-\tau) \frac{d \pi^{*}}{d \tau}=0$ can be rewritten as $(1-\tau)=\frac{\pi^{*}}{d \pi^{*} / d \tau}$. Using $\pi^{*}=F-k \cdot F^{\frac{1}{\alpha}}$ we have

$$
(1-\tau)=\frac{\pi^{*}}{L} \cdot\left[\frac{w}{\bar{e}} \frac{d \bar{e}}{d \tau}-(1-\phi) \frac{d w}{d \tau}\right]^{-1}
$$

With the conditional labor demand $L=k \cdot \frac{s}{w} \cdot F^{\frac{1}{\alpha}}$, where $k=\left((w / \bar{e})^{1-\sigma}+c^{1-\sigma}\right)^{\frac{\sigma}{\sigma-1}}$ and $F=\alpha^{\frac{\alpha}{1-\alpha}} \cdot k^{\frac{-\alpha}{1-\alpha}}$ the per capita profit becomes $\frac{\pi^{*}}{L}=\frac{w}{s} \cdot \frac{1-\alpha}{\alpha}$. Inserting this in (C2), we get

$$
\frac{(1-\tau)}{\tau} \cdot\left[\frac{\tau}{\bar{e}} \frac{d \bar{e}}{d \tau}-(1-\phi) \frac{d w}{d \tau} \frac{\tau}{w}\right]=\frac{1-\alpha}{s \cdot \alpha},
$$


which equals equation (19) with $\mu=\frac{d \bar{e}}{d \tau} \frac{\tau}{\bar{e}}$.

\section{References:}

Akerlof, G. A. and J. L. Yellen (1986) (eds.): Efficiency Wage Models of the Labor Market, Cambridge University Press, MA.

Amiti, M. and S.-J. Wei (2005): Fear of Service Outsourcing: Is It Justified?, Economic Policy 20, 307-347.

Black, S. E. and L.-M. Lynch (2000): What's Driving the New Economy: The Benefits of Workplace Innovation, NBER Working Paper 7479.

Booth, A. J. and J. Frank (1999): Earnings, Productivity, and Performed-Related Pay, Journal of Labor Economics 17, 447-463.

Cable, J. R. and F. R. FitzRoy (1980): Cooperation and Productivity: Some Evidence from West Germany's Experience, Economic Analysis and Workers Management 14, 163-190.

Cable, J. and N. Wilson (1990): Profit Sharing and Productivity: Some Further Evidence, Economic Journal 100, 550-555.

Cahuc, P. and B. Dormont (1997): Profit Sharing: Does It Increase Productivity and Employment? A Theoretical Model and Empirical Evidence on French Micro Data, Labour Economics 4, 293-319.

Cahuc, P. and A. Zylberberg (2004): Labor Economics, MIT Press.

Conyon, M. and R. Freeman (2004): Shared Modes of Compensation and Firm Performance: U.K. Evidence, in: Card, D. R. Blundell and R. B. Freeman (eds.): Seeking a Premier Economy: the Economic Effects of British Economy Reforms 1980-2000, 109-146.

Egger, H. and P. Egger (2006): International Outsourcing and the Productivity of Low-Skilled Labor in the EU, Economic Inquiry 44, 98-108.

Estrin, S., Perotin, V., Robinson, A. and N. Wilson (1997): Profit-Sharing in OECD Countries: a Review and Some Evidence, Business Strategy Review 8, 27-32.

Geishecker, I. and H. Görg (2008): Winners and Losers: A Micro-Level Analysis of International Outsourcing and Wages, Canadian Journal of Economics 41, 243-270.

Görg, H. and A. Hanley (2005): Labour Demand Effects of International Outsourcing: Evidence from Plant-Level Data, International Review of Economics and Finance 14, 365-376.

Feenstra, R. C. and G. H. Hanson (1999): The Impact of Outsourcing and HighTechnology Capital on Wages: Estimates for the United States 1979-1990, Quarterly Journal of Economics 114, 907-940. 
Fung, K. C. (1989): Profit Sharing and European Unemployment, European Economic Review 33, 1787-1798.

Hijzen, A., Görg, H. and R. C. Hine (2005): International Outsourcing and the Skill Structure of Labour Demand in the United Kingdom, Economic Journal 115, 860-878.

Holmlund, B. (1990): Profit Sharing, Wage Bargaining, and Unemployment, Economic Inquiry 28, 257-268.

Holmstrom, B. (1982): Moral Hazard in Teams, Bell Journal of Economics 13, 324340.

Holmstrom, B. and P. Milgrom (1990): Regulating Trade among Agents, Journal of Institutional and Theoretical Economics 146, 85-105.

Hsieh, C-T. and K. T. Woo (2005): The Impact of Outsourcing to China on Hong Kong's Labor Market, American Economic Review 95, 1673-1687.

Jellal, M. and Y. Zenou (2000): A Dynamic Efficiency Wage Model with Learning by Doing, Economics Letters 66, 99-105.

Jensen, M. And W. Meckling (1979): Rights and Production Functions: An Application to Labour-Managed Firms in Co-Determination, Journal of Business 52, 469-506.

Kandel, E. and E. P. Lazear (1992): Peer Pressure and Partnerships, Journal of Political Economy 100, 801-817.

Koskela, E. and J. König (2010): Can Profit Sharing Lower Flexible Outsourcing?, HECER Discussion Paper No. 310.

Kraft, K. and M. Ugarkovic (2005): Profit-Sharing: Supplement or Substitute?, Dortmund University, Working Paper.

Kruse, D. L. (1992): Profit Sharing and Productivity: Microeconomic Evidence from the United States, Economic Journal 102, 24-36.

Kruse, D. L. (1993): Does Profit Sharing Affect Productivity?, NBER Working Paper, No. 4542.

Lin, C. C., J.-J. Chang and C.-C. Lai (2002): Profit Sharing as a Worker Discipline Device, Economic Modelling 19, 815-828.

Lommerud, K. E., O. R. Straume and L. Sorgard (2006): National versus International Mergers in Unionized Oligopoly, Rand Journal of Economics 37, 212-233.

Lynn Hannan, R. (2005): The Combined Effect of Wages and Firm Profit on Employee Effort, The Accounting Review 80, 167-188.

Munch, J. R. and J. R. Skaksen (2009): Specialization, Outsourcing and Wages, Review of World Economics 145, 57-73. 
Pendleton, A., E. Poutsma, J. van Ommeren and C. Brester (2001): Employee Share Ownership and Profit Sharing in the European Union, Office for Official Publications of the European Commission, Luxembourg.

Radner, R. (1986): Repeated Partnership Games with Imperfect Monitoring and No Discounting, Review of Economic Studies 53, 43-57.

Slaughter, M. J. (2001): International Trade and Labor-demand Elasticities, Journal of International Economics 64, 27-56.

Stefanova, B. M. (2006): The Political Economy of Outsourcing in the European Union and the East-European Enlargement, Business and Politics 8, article 3.

Varian, H. (1990): Monitoring Agents with Other Agents, Journal of Institutional and Theoretical Economics 146, 153-174.

Wadhwani, S. (1988): Profit Sharing as a Cure for Unemployment, International Journal of Industrial Organization 6, 59-68.

Wadhwani, S. and M. Wall (1990): The Effects of Profit Sharing on Employment, Wages, Stock Returns and Productivity: Evidence from U.K. Micro data, Economic Journal 100, 1-17.

Weitzman, M. L. (1987): Steady State Unemployment under Profit Sharing, Economic Journal 97, 86-105. 